\title{
EGYPTIAN EOSINOPHILIC AND INFECTIOUS MENINGOENCEPHA- LITIS AND THEIR IMPACT ON PSYCHOLOGICAL ASPECTS
}

\section{By}

\author{
MAMDOUH M. M. EL-BAHNASAWY ${ }^{1}$, MOHAMMAD REDA EL FEKY ${ }^{1}$, \\ AYMAN T. A. MORSY ${ }^{2}$, MOUSA A. M. ISMAIL ${ }^{3}$ and TOSSON A. MORSY 4 \\ Military Medical Academy ${ }^{1}$, Ministry of the Interior Hospitals ${ }^{2}$, and Faculties of \\ Medicine $^{3,4}$, Cairo University ${ }^{3}$ and Ain Shams University, Cairo $11566^{4}$, Egypt
}

\section{Abstract}

Meningoencephalitis is an acute inflammation of the brain and spinal cord \& their covering protective membranes. Meningitis can be life-threatening because of the inflammation's proximity to the brain and spinal cord; therefore, the condition is classified as a medical emergency.

The commonest symptoms of meningitis are headache and neck stiffness associated with fever, confusion or altered consciousness, vomiting, and an inability to tolerate light (photophobia) or loud noises (phonophobia). Children often exhibit only nonspecific symptoms, such as irritability and drowsiness. If a rash is present, it may indicate a particular cause of meningitis; for instance, meningitis caused by meningococcal bacteria may be accompanied by a characteristic rash.

A broad variety of allergic, infectious, neoplastic, and idiopathic diseases are associated with increased blood and/or tissue eosinophilia and range in severity from self-limited conditions to life-threatening disorders. Although accepted upper limits of normal blood eosinophil numbers vary somewhat, a value above 600 eosinophils /microL of blood is abnormal in the vast majority of cases. Generally speaking, there are several possible causes of eosinophils in the CSF; undoubtedly parasitic infection is one of the main causes.

Key words: Egypt, Meningoencephalitis, Central nervous system, Parasitosis, Psychology

\section{Introduction}

Eosinophilic meningitis is defined as the presence of more than 10 eosinophils/ $\mathrm{mm}^{3}$ in the cerebrospinal fluid (CSF) and/or eosinophils accounted for more than $10 \%$ of CSF leukocytes. Reliable detection of eosinophils in the CSF requires examination of cyto-centrifuged cell preparations stained with Wright's, Giemsa, or other appropriate stains (Lo Re and Gluckman, 2003).

\section{Review and Discussion}

Eosinophils are found in the CSF in a limited number of diseases, including certain parasitic diseases and coccidioidal meningitis (Hughes et al, 2003).

Epidemiology: Although most of the infectious agents that elicit eosinophils in the CSF are parasites that are not endemic to North America and Europe (Luessi et al, 2009), cases of eosinophilic meningitis due to these parasites may be encountered in subjects who have traveled to these endemic countries (RamirezAvila et al, 2009). In addition, Angiostrongylus cantonensis, a principal agent of eosinophilic meningitis and a natural parasite of rats, has spread progressively throughout the Pacific basin and is now found in regions of North America due to ship-borne, intercontinental dissemination of infected rats (Koo et al, 1988).

Baylisascaris procyonis is a common parasite of raccoons that has tropism for the central nervous system. Human infections with this parasite have been infrequent thus far. However, the prevalence of this parasite in raccoons in the United States and the proximity of the raccoons to areas of human habitation provide opportunities for human infection to occur (Fox et al, 1988). Coccidioides immitis may also cause eosinophilic meningitis and is most prevalent in the southwestern United States. Goe et al. (2013) reported a complicated case of coccidioidomycosis occurred with dissemination to the central nervous system and its management.

Parasitic etiologies: Eosinophilia is the 
prominent in a number of parasitic diseases. Eosinophilic response to helminths is determined both by the host's immune response and by the parasite, including its distribution, migration, and development within the infected host. The level of eosinophilia parallels the magnitude and extent of tissue invasion by helminthic larvae or adults. The height of the eosinophilia peaks early in the course of infection with several helminthes since the migration of larvae is greatest at this time. However, the absence of eosinophilia does not exclude the presence of these organisms. For established infections, tissue eosinophilia around helminthes may not be accompanied by blood eosinophilia when the org anism is antigenically sequestered in tissues (e.g., intact echinococcal cysts or hydatidosis) or is limited solely to the intestinal lumen (e.g., tapeworms or adult Ascaris roundworms). Intermittent leakage of fluids from echinococcal cysts can transiently stimulate increase in blood eosinophilia and elicit urticaria, bronchospasm, or anaphylaxis (Georgiou et al, 2005)

Angiostrongylus cantonensis, Baylisascariasis, and gnathostomiasis are the three predominant parasitic infections associated with the eosinophilic meningitis. The causative agents are helminthic parasites, the multicellular metazoans or "worms", which are typically associated with blood eosinophilia. In contrast, eosinophilia is not commonly seen with the unicellular protozoan parasites. Since the three helminths are naturally parasites of animals, human infections are zoonoses. Human infections are self-limited because larvae do not replicate or mature to adulthood in humans. With each of these parasitic infections, the eosinophilic meningitis is caused by the migration of larvae within the nervous system. For both $A$. cantonensis and B. procyonis, parasites localize within the nervous system naturally in animals and in humans when they are incidentally infected. In gnathostomiasis, larvae can migrate anywhere, penetrating the nervous system and/or non-nervous tissues (Tefferi, 2005).

Generally speaking, A. cantonensis is one of the commonest parasites to cause the eosinophilic meningitis. Eosinophilic meningitis due to $A$. cantonensis occurs principally in Southeast Asia, particularly Thailand and Malaysia, and throughout the Pacific basin, including Indonesia, the Philippines, Taiwan, China, Japan, Papua New Guinea, Hawaii, and several smaller Pacific islands. The parasite has also been found outside of this broad area in regions of Africa, Australia, Cuba, Puerto Rico, and Jamaica, and has spread from New Orleans into other areas of Louisiana (Hochberg et al, 2007).

The life cycle of $A$. cantonensis, the rat lungworm, involves its natural mammalian host, the rat, and intermediate molluscan hosts. Humans become infected by ingesting: Raw, infected terrestrial mollusks, such as snails and slugs Vegetables or vegetable products contaminated by mollusk slime or infected planarian Carrier hosts such as freshwater and terrestrial crabs and freshwater shrimp that have eaten infected mollusks (Tsai et al, 2004). Thus, residents in endemic areas as well as tourists or visitors who may partake of local foods are at risk for infection. Children who play in the dirt are at special risk. A father and his two sons were reported to have eosinophilic meningitis due to $A$. cantonensis in Vietnam after the consumption of a celebratory meal of raw snails (Chau et al, 2003). The outbreaks of infection were uncommon even in endemic areas. However, an outbreak of eosinophilic meningitis caused by $A$. cantonensis was reported among travelers returning from Jamaica (Slom et al, 2002).

Clinical manifestations: Larvae of $A$. cantonensis are inherently neurotropic and, following ingestion by humans, migrate into neurologic or ocular tissues. Ocular involvement due to intravitreal larvae is less common than neurologic involvement and may be manifest by unilateral blurring of vision without signs of 
meningitis (Kumar et al, 2005). Neurologic symptoms develop after a period ranging from 2 to 35 days following infection. The disease usually presents as transient meningitis or, less frequently, as a more severe disease involving the brain, spinal cord, and nerve roots. Fatalities, while not commonly occur (LIndo et al, 2004).

Excruciating headache is the most commonest presenting symptom in than $90 \%$ of patients and is usually frontal, occipital, or bitemporal. The headache typically is rapidly relieved by lumbar puncture. Neck stiffness, nausea, vomiting, and paresthesias are also frequent but fever may be absent (Tsai et al, 2001). In the Jamaican outbreak cited above, paresthesias or hyperesthesias of the arms, legs, trunk, or all three sites were present in 9 of the 12 patients (75\%). Paresthesias with residual areas of hyperesthesia often persist for several weeks, even after other symptoms have resolved. Paralysis of the extraocular muscles or facial nerves develops in 4 to 9 percent of patients, but usually resolves with time (Eamsobhana et al, 2003).

Diagnosis: The diagnosis of cerebral angiostrongyliasis is generally based upon the clinical presentation, CSF eosinophilia, and an epidemiologic history of known or possible exposure to infective A. cantonensis larvae. The diagnosis requires the finding of CSF eosinophilia. The CSF is usually cloudy, but not grossly turbid or xanthochromic. The CSF leukocyte count ranges from about 20 to 5000 cells $/ \mathrm{mm} 3$ and is usually between 150 and 2000 cells $/ \mathrm{mm} 3$. The CSF eosinophilia exceeds $10 \%$ in approximately $95 \%$ of cases and is usually in the range of 20 to $70 \%$. The CSF protein concentration is usually elevated, but the glucose concentration is normal or only minimally reduced. Peripheral blood eosinophilia usually accompanies eosinophilic CSF pleocytosis. It is greater than $3 \%$ in the majority of patients. Blood eosinophilia does not correlate with CSF eosinophilia or with the clinical course (Podwall et al,
2004).

Since larvae of $A$. cantonensis have only rarely been recovered from the CSF antemortem, the diagnosis does not depend on detecting and identifying the causative agent. Enzyme-linked immunosorbent assay (ELISA) testing helps to confirm the diagnosis, but at present is principally available through Mahidol University, Bangkok, Thailand (Tsai et $a l, 2003)$. The absence of focal lesions on CT scan helps to distinguish this form of eosinophilic meningitis from neurocysticercosis or gnathostomiasis. MRI imaging is also of value. In a study from Taiwan of 13 patients with $\mathrm{A}$. cantonensis eosinophilic meningitis who underwent MRI imaging of the brain, the MRI scans revealed high signal intensities over the globus pallidus and cerebral peduncle on T1-weighted imaging, leptomeningeal enhancement, ventriculomegaly, and the punctate areas of abnormal enhancement within the cerebral and cerebellar hemisphere on gadolinium-enhancing T1 imaging, and a hyperintense signal on T2weighted images. There was a significant correlation between severity of headache, CSF pleocytosis, and CSF and blood eosinophilia with MRI signal intensity in T1-weighted imaging (Jin et al, 2003).

The treatment of cerebral angiostrongyliasis consists principally of supportive measures without administration of an anthelminthic agent. Repeat lumbar punctures may provide symptomatic relief. In the absence of reinfection, migrating larvae die over time and the accompanying inflammation subsides. Thus, most patients with the cerebral angiostrongyliasis have a self-limited course and recover completely; fatalities are uncommon. In one study of 484 cases of eosinophilic meningitis in Thailand, for example, the mortality rate was less than $0.5 \%$ (Chotmongkol et al, 2000).

There is limited but increasing information concerning the use of corticosteroids and/or anthelminthic treatment. One randomized double-blind study examined 
the clinical efficacy of $60 \mathrm{mg} /$ day of prednisolone for two weeks in 110 patients with eosinophilic meningitis (Chotmongkol and Sawanyawisuth, 2002). There were significant differences favoring the use of corticosteroids with regard to persistence of headache (5 vs. 25 , respectively; $\mathrm{P}=.00004)$ and the patients who required repeat lumbar puncture for symptomatic relief ( 7 vs. 22 , respectively). Corticosteroids, however, were not beneficial in 7 of 11 comatose patients with severe eosinophilic meningitis. Clinical exacerbation of eosinophilic meningitis following anthelminthic treatment has been reported, perhaps consonant with concerns that anthelminthic-induced parasite death may elicit pro-inflammatory responses within vulnerable organs e.g., the eye or CNS (Chotmongkol et al, 2009). In a randomized trial of 104 patients with $A$. cantonensis eosinophilic meningitis, additional of albendazole to prednisolone therapy was useless for headache alleviation (Chotmongkol and Sawanyawisuth, 2008).

Repeat lumbar punctures for symptomatic relief in those with marked headaches were recommended. Adjunctive corticosteroid therapy can be instituted for those with marked headaches as well as those with prominent neurologic manifestations. But, not advise using anthelminthic agents for those with neurologic or ocular disease in the absence of information on their benefit and out of concern that anthelminthic treatments might elicit deleterious inflammatory responses within nervous system or ocular structures. In rare setting of ocular disease, options include surgery or laser therapy (Nawa et al, 2005).

Gnathostomiasis: Eosinophilic meningitis due to $G$. spinigerum results from the migration of larvae of the parasite within human tissues (Punyagupta et al, 1990). In contrast to $A$. cantonensis larvae, $G$. spinigerum larvae are not primarily neurotropic, but may migrate in subcutaneous, visceral, or neural tissues. Conse- quently, gnathostomiasis can present as migratory cutaneous swellings and less commonly as eosinophilic meningoencephalitis or inflammatory masses in visceral organs (Moore et al, 2003). The migrating third stage larvae of Gnathostoma cause localized swellings that typically last one to two weeks and are associated with edema, pain, itching and variable erythema (Crowley and Kim, 1995).

Lesions begin as early as three to four weeks after ingestion of the parasite, although the swelling can continue to appear months to years later since the parasite can survive for years. One or multiple parasites may be present and can migrate to tissues throughout the body, including the CNS, gastrointestinal or genitourinary tracts, lungs, and eye (Ligon, 2005).

Gnathostomiasis is endemic in Southeast Asia and parts of China and Japan and occurs in Europe, Central and South America, Africa, and the Middle East. In travelers to endemic regions, gnathostomiasis, principally due to its subcutaneous presentations, is increasingly encountered. Adult G. spinigerum worms are gastrointestinal parasites of domestic and wild dogs and cats. Infective third-stage larvae develop in the flesh of many animal species including fish, frogs, eels, snakes, chickens, and ducks that have either eaten infected Cyclops or another infected second intermediate host. Man usually acquires infection by eating the raw or undercooked fish and/or poultry (Sawanyawisuth et al, 2005).

Clinical symptoms are elicited by the migration of one or more Gnathostoma larvae in cutaneous, visceral, neural, or ocular tissues. Larval penetration into the brain usually results from the migration along a nerve tract. Affected patients typically present with sudden onset of severe radicular pain or headache as well as paresthesias in the trunk or a limb, followed shortly by paralysis of extremities or cranial nerves. As a result of increasingly exotic tastes for local ethnic dishes, including raw seafood, some regions out- 
side of gnathostome-endemic areas import live species for raw consumption, which facilitate imported human gnathostomiasis or potentially the establishment of this zoonosis in formerly nonendemic regions. Traveling to a gnathostome-endemic area is no longer a criterion for diagnosis (Diaz, 2015).

The CSF is often xanthochromic or bloody in CNS gnathostomiasis with an eosinophilic pleocytosis. The CSF protein concentration is elevated but the glucose concentration is usually normal. Larvae can almost never be recovered from the CSF. Peripheral blood eosinophilia is often quite pronounced and greater than that seen in angiostrongyliasis. Computed tomographic scans can demonstrate areas of hemorrhage, and gnathostomiasis may be mistaken for cerebral hemorrhage due to primary cerebro-vascular disease. MRI imaging may show abnormal enhancement and enlargement in cauda equina gnathostomiasis and hemorrhage in intracerebral gnathostomiasis. The serologic tests were developed but are not readily available outside of highly endemic areas. Ultrasound biomicroscopy has been reported to be effective in diagnosis of the intraocular gnathostomiasis (Bhende et al, 2005).

The syndrome of eosinophilic meningoencephalitis due to gnathostomiasis is usually more fulminant than infection due to angiostrongyliasis. Furthermore, the tissue destruction and severe inflammation in gnathostomiasis may result in acute cerebral hemorrhages, which can be large and rapidly fatal (Germann et al, 2003). Although there are no controlled trials in CNS gnathostomiasis to document the efficacy of corticosteroids, their utility in suppressing inflammation suggests their use. There are also no data on whether anthelminthic treatment of CNS gnathostomiasis is beneficial or perhaps deleterious due to augmented inflammation from dying larvae. In cutaneous gnathostomiasis, both the ivermectin and albendazole were evaluated without de- monstrable differences, but neither has been tested blindly versus the placebo (Bussaratid et al, 2005)

Baylisascariasis: As reported above, the Baylisascaris procyonis is an ascarid parasite of raccoons that is widely prevalent within raccoon populations in regions of the United States. In a study in three northern California communities, 28 to $49 \%$ of residential properties surveyed harbored at least one raccoon latrine that was positive for $B$. procyonis eggs. The presence of $B$. procyonis eggs in raccoon latrines was common, widespread, and closely associated with human habitation. In DeKalb County, Georgia, 22\%of raccoons were infected (Roussere et al, 2003). B. procyonis has been only rarely caused human eosinophilic meningoencephalitis. B. procyonis eggs are shed in raccoon feces; ingestion of infectious eggs is followed by release of larvae, which have a predilection to migrate into the spinal cord and brain. Thus, this syndrome can be considered a form of visceral larva migrans. More than a dozen cases of human eosinophilic meningoencephalitis due to $B$. procyonis were reported in children who had probably ingested raccoon feces. Several of the children died and the others were left with permanent neurologic sequelae. Those at risk include children, with their proclivity for pica, and, less likely, adults who consume foodstuffs or other items contaminated with the embryonated, infectious Baylisascaris eggs derived from raccoon feces (Eberhard et al, 2003).

Ocular findings, diffuse unilateral subacute neuroretinitis and choroidal infiltrates in association with neurologic disease, have been noted in two patients. The diagnosis is made in a patient with meningitis, although ocular involvement may develop without CNS involvement, and potential exposure to the raccooncontaminated soil that also has prominent blood and CSF eosinophilia. Definitive diagnosis would require the morphologic identification of larvae, which would ne- 
cessitate examination of biopsied tissue. While serologic tests have been developed, they are not readily available and their sensitivities and specificities have not been ascertained (Mets et al, 2003).

Other helminthic parasites, whose eggs or larvae can sometimes be localized within the CNS, may elicit an eosinophilic pleocytosis. These include cerebral and spinal cord schistosomiasis, as Schistosomal myelopathy occurred relatively frequently in Malawi (Naus et al, 2003), toxocariasis canis or visceral larva migrans (Robinson et al, 2002), trichinellosis (Nikolić et al, 1988), echinococcosis caused a meningeal hydatid cyst (Bottieau et al, 2003), neurocysticercosis (Valadas et al, 2015), fascioliasis (Arjona et al, 1995), cerebral paragonimiasis (Xia et al, 2015) and Pypen et al. (2015) reported a rare case of Strongyloides stercoralis meningitis in an immunocompromised patient treated for a lung carcinoma.

As to tissue filariasis, Bhalla et al. (2013) mentioned that filaria may locate anywhere in the human body. Their neurological manifestations are increasingly recognized particularly with Onchocerca volvulus or Loa loa infections, Wuchereria bancrofti, or Mansonella perstans. The risk of developing these manifestations may also increase in cases that harbor multiple filariasis or co-infections, for instance as with malaria. The pathogenesis of neurological manifestations of these infections is complex; however, pathogenic reactions may be caused by mechanical disruption, e.g., the degeneration often followed by granulomas, causing fibrosis or mass effects on other tissues, vascular lesions, e.g., vascular block of cerebral vessels, or disordered inflammatory responses resulting in meningitis, encephalitis or localized inflammatory responses.

Apart from helminthes, cerebral toxoplasmosis was reported (Prandota et al, 2014), malaria (Mayor, 2015), human African trypanosomes (Courtioux et al,
2009), American trypanosome (Sartori et $a l, 2007)$ and cases of meningitis leishmaniosis caused by Leishmania infantum in naturally infected dogs (Viñuelas et al, 2001). Shih and Koeller (2015) reported that in central nervous system: In terms of potential exposure in the worldwide population, parasitic infections, including neurocysticercosis, toxoplasmosis, echinococcosis, malaria, and schistosomiasis, are the greatest threat. Rare amebic infections are noteworthy for their extreme virulence and high mortality.

Apart from endo-parasites, visceral myiasis, with central nervous system invasion by larvae of cattle botflies, may also elicit a CSF eosinophilia. Sartin et al. (1986) in USA reported a second instar Cuterebra larva was found in the thickened meninges of a 6-week-old female Doberman pinscher at necropsy. The dog appeared blind and had chewing fits before death. François et al. (1987) in France reported a 9-year old country boy developed blepharitis with inflammation of the face and, 1 month later, eosinophilic meningitis with paralysis of 3 limbs and of an abducent nerve. Nuclear magnetic resonance imaging of the central nervous system disclosed a lesional signal beneath the floor of the 4th ventricle, which was compatible with the presence of a larva of fly. Treatment with thiabendazole was tried, and the clinical signs regressed. Six months later, an asymmetrical hydrocephalus due to obstruction of Monroe's foramen by an inflammatory granuloma was discovered. Human hypodermyasis, due to migration in tissues of larvae of flies, was not rare in the cattle-breeding areas. Sharma et al. (1989) in India reported human nasal myiasis by dipterous larvae of the fly of genus Chrysomyia species. It is prevalent in tropical countries. They added that the maggots could cause extensive erosion of the nose, face and intra-cranial structures occasionally causing the meningitis and then death. Cheshier et al. (2007) in USA reported that after a minor motor vehicle 
accident, police brought a 75-year-old man to the emergency room because he was observed to have a large cranial lesion. Examination revealed a $15 \times 17 \mathrm{~cm}$ frontal bone defect with eroded frontal dura, exposed cortex, and massive cortical maggot infestation Terterov et al. (2010) stated that only eight cases of cerebral myiasis in humans have been reported worldwide and only one in the United States. They added the case of cerebral myiasis in the setting of head trauma in suburban Los Angeles.

Nonparasitic infectious etiologies: The coccidioidomycosis is the one fungal infection that is notably associated with the CSF eosinophilia when infection disseminates to involve meninges (Ismail and Arsura, 1993). In one series, for example, the eosinophils were present in the CSF in $70 \%$ of cases of coccidioidal meningitis, and $30 \%$ met the criteria for the eosinophilic meningitis (Kuberski, 1979). Thus, this data was an appropriate clinical setting should raise concern for coccidioidal infection. In comparison, CNS cryptococcosis is only rarely accompanied by CSF eosinophilia (Schermoly and Hinthorn, 1988). Nevertheless, a case of fatal Cryptococcus meningitis with intraventricular granuloma was reported (Muller et al, 1978). Generally, some viral, rickettsial and bacterial infections are associated with CSF eosinophilia which were rare and non-causes of eosinophilic meningitis at least in animals (Uchida et al, 1993).

Noninfectious Etiologies: Hypereosinophilic syndrome is the leukoproliferative disorders characterized by a sustained blood eosinophilia in excess of 1500/ $\mathrm{mm}^{3}$ without any parasitic, allergic, or other etiologies. While eosinophilic meningitis has been described in association with these disorders, it is not one of the more frequent neurologic manifestations (Sheikh and Weller, 2007). The neoplastic diseases are the most frequently.

Hodgkin lymphoma can be an associated eosinophilic CSF pleocytosis. Cancer arising outside the central nervous system (CNS) can metastasize to any intracranial structure, including the membranes covering the brain. These membranes consist of the Dura mater, and the arachnoid and Pia mater, which together are called the leptomeninges. The subarachnoid space lies between the arachnoid and pia mater and contains the cerebrospinal fluid (CSF) and arteries supplying the brain parenchyma. Tumor involvement of the leptomeninges is associated with spread of malignant cells throughout the subarachnoid space, producing signs and symptoms due to multifocal involvement (Kesari and Batchelor, 2003).

Eosinophilia in the CSF developed with medications, including the Ibuprofen, Ciprofloxacin, Trimethoprim-sulfamethoxazole, and intraventricular Vancomycin or Gentamicin (Patey et al, 1988), the Ibuprofen caused eosinophilic meningitis in a healthy girl (Bansal et al, 2014) and Isoniazid, anti-tuberculosis drug for two months as acute eosinophilic myocarditis (Zhang et al, 2015). Sterile CSF eosinophilia has also been noted after myelography with contrast agents and can accompany ventriculoperitoneal shunt implantation or malfunction (Traynelis et al, 1988). In one series of children with ventriculoperitoneal shunts, approximately one-third experienced a CSF eosinophilia of more than $8 \%$ in the absence of peripheral blood eosinophilia; these patients were more likely to experience shunt infections and require shunt revisions (Tung et al, 1991). Other conditions described with eosinophilic meningitis include sarcoidosis and cerebral eosinophilic granuloma (Scott, 1988).

\section{Egyptian parasites and meningitis}

As to the Angiostrongylus cantonensis, Abo-Madyan et al. (2005) in Al-Fayoum Governorate reported Physa acuta harbored the immature stage of the nematode parasite Parastrongylus cantonensis. Ibrahim (2007) at Al-Salam irrigation Canal and Al-Abtal village (Northern Sinai Governorate) reported A. cantonensis a 
wide range of freshwater snails and $\mathrm{Me}$ lania tuberculata snail as a new intermediate host.

As to schistosomiasis: Othman and Soliman (2015) reported that the disease plagued the Egyptian population since the antiquity and still a public health problem in Egypt, despite the tendency of being overlooked.

As to fascioliasis: Rashed et al. (2010) mentioned that about 24 million Egyptians at risk and about 800,000 were infected. They added that ectopic fascioliasis (EF) has direct and indirect effects on both humans and animals. EF was individual cases in the period from 1950 up to the end of last century with Fasciola hepatica the commonest species in most cases

As to echinococcosis: it was well documented in nearly all governorates among man, animals and dogs. Haridy et al. (2008) added cystic hydatidosis is a zoonotic silent health problem and that one must keep in mind that infected dogs are asymptomatic and human hydatidosis are typically asymptomatic except a few cases of long standing and heavy infections that may be fatal.

As to Taenia solium, Bruschi et al. (2006) described an ancient case of cysticercosis discovered in an Egyptian mummy of a young woman of about 20 years of age who lived in the late Ptolemaic period (second to first centuries B.C.). Microscopically lesion sections revealed a cystic structure, with a wall, with numerous projecting eversions, a characteristic feature of cysticercosis of the human Taenia solium. They concluded that, in Hellenistic Egypt, farming of swine, along with man an intermediate host of this parasite, were present, and supported other archeological evidence.

As to toxocariasis: El Shazly et al. (2011) studied the various clinical phenotypes of toxocariasis in 480 symptomatic children attending the Children's Hospital, Mansoura University. Patients were examined clinically, and by ELISA anti-
Toxocara antibodies. They concluded that visceral larva migeans was underestimated andthat the degree of eosinophilia was found to be positively correlated to the optical density (OD) ELISA of antiToxocara IgG.

As to Strongyloides stercoralis; Geneidy and El-Hamshary (2012) reported a fatal case of chronic strongyloidiasis is reported in an immunocompromized patient with complicated pulmonary infection.

As to trichinellosis: Pozio (1991) reported that Domestic T. spiralis spiralis was present in Spain, France, Yugoslavia, Egypt, Gambia, and Nigeria in domestic and/or sylvatic animals. In Africa human trichinellosis is rare, mostly from religious and food habits. Morsy et al. (2000) reported that examination of pigs in governmental slaughtered houses over the last five years showed an overall rate of $1.691 \%$.

Free-living amoebas are protozoan parasites can survive and replicate in the environment without requiring a host. There are many different amebic organisms that can be found in the environment, but four genera that can cause significant clinical disease in humans are Naegleria, Acanthamoeba, Balamuthia, and Prototheca. Infections with these free-living amebas are quite uncommon. However, they can cause severe neurologic disease in humans, which is often fatal. Also, Acanthamoeba species can cause keratitis. $N$. fowleri is found worldwide, particularly in warm bodies of water such as manmade lakes and ponds, hot springs, and thermally polluted streams and rivers. They cannot survive in seawater. The organism has been isolated from nasal passages and throats of healthy individuals and seroprevalence studies have shown that many individuals from endemic areas for PAM have positive antibody titers. Disease typically occurs in previously healthy children and young adults. Affected individuals characteristically have a recent history of water-sports activities 
in lakes, ponds, or inadequately chlorinated swimming pools (Schuster and Visvesvara, 2004). N. fowleri exists in the environment in three forms: trophozoite, which is the reproductive stage that feeds on bacteria resistant cyst transient flagellate form $N$. fowleri gains access to the CNS via the olfactory epithelium, traverse the cribriform plate to reach the brain. Although infection is typically associated with swimming or fresh water contact or via inhalation of contaminated dust is also possible (Visvesvara and Maguire, 2006).

Typical presentation of PAM resembles bacterial meningitis, with the acute onset of headache, fever, neck stiffness, nausea, and vomiting. Alterations in taste and smell may be noted initially, perhaps because of involvement of the olfactory nerve. Patients do not respond to routine antibiotics, and progressive deterioration occurs. Seizures, ataxia, cranial nerve palsies, confusion, and coma frequently develop.

PAM is fatal in more than $95 \%$ of cases, usually within four to six days. Death usually results from raised intracranial pressure leading to brain herniation. The diagnosis is infrequently made premortem, although a few survivors have been reported (Jain et al, 2002). PAM patients often have an elevated peripheral white blood cell (WBC) count, usually with a predominant increase in polymorphonuclear leukocytes (PMNs). However, these findings are nonspecific. The cerebrospinal fluid (CSF) will have features resembling bacterial meningitis including elevated opening pressure, PMN pleocytosis, increased protein, and low glucose. Imaging of the brain may show the cerebral edema, leptomeningeal enhancement (particularly in the basal meninges), and areas of hemorrhage and necrosis. Microscopy is valuable either directly on CSF or on histologic sections of brain. N. fowleri is found in humans in the trophozoite form only; the cyst form is not seen. The motile trophozoite can often be seen on CSF wet mount examination or can be stained with Wright's or Giemsa stains. The organism is not visible on Gram stain. A wet mount examination should be performed in untreated patients who present with a purulent meningitis and no bacteria visible on Gram stain in order to exclude the diagnosis of PAM.

In Egypt, the occurrence of heat-tolerant Naegleria spp., especially the $N$. fowleri, which was reported in immunocompromised hosts (El-Fakahany et al, 1997) and in different Egyptian water bodies even in the Nile River (Nashed et al, 1991; Antonios, 2010; Khalifa et al, 2014; Al-Herrawy and Gad, 2015) should be considered as a potential public health water borne threat.

As to myiasis, Steyskal and El-Bialy (1967) listed the Egyptian Dipterous among which 184 were myiasis producing colored flies. They were in alphabetical orders; Calliphoridae (12 species), Gasterophilidae (five species), Muscidae (63 species), Oestridae (five species), Piophilidae (two species) and Sarcophagidae (97 species) and gave key for the families identifications. Shaumar et al. (1989) established a key of all known Egyptian species of Calliphoridae to genera and species accompanied by synonyms in the light of modern taxonomic concepts. Eight genera are recorded including 14 species and added Hemipyrellia pulchra (Wied) as a record. Morsy (2014) reported that apart from the blood suckers or the insect- borne diseases, others, almost non-blood suckers attack man and animal to deposit their eggs or larvae of myiasis producing flies in skin, nose, eye, lung, ear, anus, vagina, and oral cavity as well as accidental gastrointestinal ones causing pathogenic condition known as myiasis causing different pathogenic conditions. Nosocomial myiasis must be noted carefully, especially in case of hospitalized patients. He added that not less than the nosocomial myiasis illustrates an unusual problem that might 
confront those responsible for infection control programs. But, still little is known about such an important subject in Egypt, although not less than one hundred authors dealt with myiasis in man and animals.

On the other hand, El-Bahnasawy and El-Gohary (2015) in Almaza Military Fever Hospital evaluated meningitis during the last eight years (from 2000-2007). Etiology of cases of acute meningitis was as follows: the Streptococcus pneumoniae $(39.6 \%)$, Viral (39.6\%), staphylococci (14.6\%), Tuberculous (4.2\%) and Haemophilus influenzae type B (2.1\%). None of meningococcal meningitis was all-over the period of the study i.e. from 20002007. Handicapping occurred in $(2.1 \%)$ and it was post-pneumococcal in the form of intellectual deterioration (impaired memory and concentration). Mortality was generally relatively low. Case fatality rate for cases of acute meningitis was $(8.3 \%)$, case fatality rate for acute bacterial meningitis was $(13.8 \%)$, with lowest case fatality rate in viral meningitis $(0 \%)$ and tuberculous meningitis $(0 \%)$, and the highest case fatality rate in cases of Staphylococcal meningitis (40\%). Recovery occurred in $(91.7 \%)$ with complete recovery in $(89.6 \%)$ and $(2.1 \%)$ recovered with neurological sequelae.

\section{Routine Nursing Role (CDC, 2007)}

1- Perform frequent vital signs and neurologic assessments for disease progression, such as decreased level of consciousness. Assess mental status, muscle strength, headache severity, and pupillary reactions. Maintain a patent airway, suctioning the patient as needed and positioning him to encourage drainage of oral and nasal secretions. Monitor oxygenation and administer supplemental oxygen if indicated. Assess him for cyanosis and dyspnea and monitor his arterial blood gas analysis results.

2- Keeping your patient's room quiet and darkened can make him more comfortable and reduce his agitation. Group your nursing interventions to minimize the stress of repeated procedures, and limit visitors and other sources of stimulation.

3- Assess the patient's ability to swallow. Advocate for a swallow study, if indicated, as well as for a nutritional consult; he may need enteral or parenteral nutrition. 4- Patient may need an indwelling urinary catheter for accurate intake and output monitoring. Provide meticulous skin care to prevent skin breakdown. If he's extremely diaphoretic, change the bed linens frequently to prevent skin irritation. While he's on bed rest, apply graduated compression stockings to prevent venous thromboembolism.

5-Take safety precautions as raising the side rails and bed in low position when the patient is alone, and observe him frequently. Make sure any catheters are secured so they can't be dislodged by patient movement.

6- Facilitate communication, support and education for the patient and his family and the health care team, as the recovery period may be prolonged. Families may need a lot of teaching and support to understand the changes taking place in their loved one. Arrange for a social service consult early in the hospitalization.

\section{Conclusion}

Meningoencephalitis is an inflammation of the brain \& meninges (the lining of the brain and spinal cord). Based upon the history, physical examination and CSF findings, patients can often be classified as having probable bacterial or viral or parasitic meningitis or even noninfectious cause, although overlap can be frequent, particularly if bacterial meningitis has been partially treated with previous antibiotics. Organic brain syndromes are associated with both protozoan and helminthic infections; drugs side-effects commonly used to treat parasites may impair mood and cause anxiety, agitation or psychosis.

Thus, the physicians when dealing with meningoencephalitis must kept in mind the commonest parasitic disease of the CNS encountered in Egypt. 
It must be in mind by Internists, Neurologists, Neurosurgeons, Pathologists, Parasitologists and Nursing Staff caring for meningoencephalitis patients.

\section{References}

Abo-Madyan, AA, Morsy, TA, Motawea, S M, El Garhy, MF, Massoud, AM, 2005: Spot light survey on fresh-water snails of medical importance in Al Fayoum Governorate, Egypt. J. Egypt. Soc. Parasitol. 35, 1:49-58.

Al-Herrawy, AZ, Gad, MA, 2015: Isolation and molecular identification of Naegleria fowleri from Nile River, Egypt. J. Egypt. Publ. Hlth. Assoc. 90, 4:161-5.

Antonios, SN, 2010: Scanning electron microscopic study of trophozoite and cyst stages of Naegleria fowleri. J. Egypt. Soc. Parasitol. 40, 1:271-6.

Arjona, R, Riancho, JA, Aguado, JM, Salesa, R, González-Macías, J, 1995: Fascioliasis in developed countries: a review of classic and aberrant forms of the disease. Medicine (Baltimore) 74, 1:13-23.

Bansal, S, Gupta, M, Sharma, D, Bansa, I S, 2014: A rare case of Ibuprofen-induced eosinophilic meningitis in a 13 -year-old girl. Clin. Med. Insights Pediatr. 18; 8:3-4.

Barakat, AM, Salem, LM, El-Newishy, A M, Shaapan, RM, El-Mahllawy, EK, 2012: Zoonotic chicken toxoplasmosis in some Egyptians governorates. Pak. J. Biol. Sci. 15, 17:821-6.

Bhalla, D, Dumas, M, Preux, PM, 2013: Neurological manifestations of filarial infections. Handb. Clin. Neurol. 114:235-42.

Bhende, M, Biswas, J, Gopal, L, 2005: Ultrasound biomicroscopy in the diagnosis and management of intraocular gnathostomiasis. Am. J. Ophthalmol. 140:140-52.

Bottieau, E, David, P, Dewitte, O, Jacobs, F, 2003: Eosinophilic meningitis following incomplete resection of a meningeal hydatid cyst. Scand. J. Infect. Dis. 35:898-904.

Bruschi, F, Masetti, M, Locci, MT, Ciranni, R, Fornaciari, G, 2006: Short report: Cysticercosis in an Egyptian mummy of the late Ptolemaic period. Am. J. Trop. Med. Hyg. 74, 4:598-9.

Bussaratid, V, Krudsood, S, Silachamroon, U, Looareesuwan, S, 2005: Tolerability of ivermectin in gnathostomiasis. Southeast Asian J. Trop. Med. Pub. Hlth. 36:644-52. CDC, 2007: Guideline for Isolation Precautions: Preventing Transmission of Infectious
Agents in Healthcare Settings 2007. http:// cdc.gov/ncidod/dhqp/gl_isolation.html.

Chau, TT, Thwaites, GE, Chuong, LV, et al, 2003: Headache and confusion: The dangers of a raw snail supper. Lancet 361:1866.

Cheshier, SH, Bababeygy, SR, Higgins, D, Parsonnet, J, Huhn, SL, 2007: Cerebral myiasis associated with angiosarcoma of the scalp: case report. Neurosurgery 61, 1: E167.

Chotmongkol, V, Kittimongkolma, S, Niwattayakul, $\mathrm{K}$, et al, 2009: Comparison of prednisolone plus albendazole with prednisolone alone for treatment of patients with eosinophilic meningitis. Am. J. Trop. Med. Hyg. 81:443-9.

Chotmongkol, V, Sawanyawisuth, K, 2002: Clinical manifestations and outcome of patients with severe eosinophilic meningoencephalitis presumably caused by angiostrongylus cantonensis. Southeast Asian J. Trop. Med. Pub. Hlth. 33:231-40.

Chotmongkol, V, Sawanyawisuth, K, Thavornpitak, YA, 2000: Corticosteroid treatment of eosinophilic meningitis. Clin. Infect. Dis. 31:660-8.

Courtioux, B, Pervieux, L, Vatunga, G, Marin, B, Josenando, T, et al, 2009: Increased CXCL-13 levels in human African trypanosomiasis meningoencephalitis. Trop. Med. Int. Hlth. 14, 5:529-34.

Crowley, JJ, Kim, YH, 1995: Cutaneous gnathostomiasis. J. Am. Acad. Dermatol. 33: 825-32.

Diaz, JH, 2015: Gnathostomiasis: An emerging infection of raw fish consumers in Gnathostoma nematode-endemic and nonendemic countries. J. Travel Med. 2015 May 22. doi: 10.1111/jtm.12212.

Eamsobhana, P, Yoolek, A, Kreethapon, N, 2003: Blinded multi-laboratory evaluation of an in-house dot-blot ELISA kit for diagnosis of human parastrongyliasis. Southeast Asian J. Trop. Med. Pub. Hlth. 34:1-12.

Eberhard, ML, Nace, EK, WOn, KY, et al, 2003: Baylisascaris procyonis in the metropolitan Atlanta area. Emerg. Infect. Dis. 9: 1636-42.

El-Bahnasawy, MMM, El-Gohary, GE, 2015: A study of records of meningitis cases admitted to Almaza Military Fever Hospital from 2000-2007. EMMJ, 70, 1:21-39

El-Fakahany, AF, Fahmy, RR, Mohamed, AS, 1997: Free living amoebae as opportunistic parasites in immunocompromised hosts. J. Egypt. Soc. Parasitol. 27, 2:515-27. 
El-Kady, IM, 2011: T-cell immunity in human chronic toxoplasmosis. J. Egypt. Soc. Parasitol. 41, 1:17-28.

El Shazly, AM, Attia, G, El-Ghareeb, AS, Belal, US, 2011: Clinical varieties of toxocariasis canis in Children's Hospital, Mansoura University: is it an underestimated problem? J. Egypt. Soc, Parasitol. 41, 2:263-74.

Elsheikha, HM, Aboul-Dahab, MA, Abdel Maboud, AI, El-Sherbini, E, 2009: Prevalence \& risk factors of Toxoplasma gondii antibodies in asymptomatic Egyptian blood donors. J. Egypt. Soc. Parasitol. 39, 1:S351-61. Fox, AS, Kazacos, KR, Gould, NS, et al, 1985: Fatal eosinophilic meningoencephalitis and visceral larva migrans caused by the raccoon ascarid Baylisascaris procyonis. N. Engl. J. Med. 312:1619-24.

François, P, Martin, G, Goullier, A, Plasse, M, Beaudoing, A, 1987: Neuromeningeal hypodermyiasis complicated by hydrocephaly: Value of nuclear magnetic resonance imaging. Presse Med. 16, 25:1231-3

Fuller, DO, Parenti, MS, Hassan, AN, Beier, JC, 2012: Linking land cover and species distribution models to project potential ranges of malaria vectors: an example using the Anopheles arabiensis in Sudan and Upper Egypt. Malar. J. 11:264-72.

Geneidy, MR, El-Hamshary, NK, 2012: A fatal case of strongyloidiasis stercoralis superinfection in an immunocompromized patient. J. Egypt. Soc. Parasitol. 42, 3:691-6. Georgiou, S, Maroulis, J, Monastirli, A, et al, 2005: Anaphylactic shock as the only clinical manifestation of hepatic hydatid disease. Int. J. Dermatol. 44:233-40.

Germann, R, Schächtele, M, Nessler, G, Seitz, U, Kniehl, E, 2003: Cerebral gnathostomiasis as a cause of an extended intracranial bleeding. Klin. Padiatr. 215, 4:223-5.

Goe, A, Swenson, J, West, G, Evans, J, 2013: Meningoencephalitis with secondary obstructive hydrocephalus caused by probable coccidioides species in a buff-cheeked gibbon (Nomascus gabriellae). J. Zoo Wildl. Med. 44, 3:781-5.

Haridy, FM, Holw, SA, Hassan, AA, Morsy, TA, 2008: Cystic hydatidosis: A zoonotic silent health problem. J. Egypt. Soc. Parasitol. 38, 2:635-44.

Haridy, FM, Saleh, NM, Khalil, HH, Morsy, TA, 2010: Anti-Toxoplasma gondii antibodies in working donkeys and donkey's milk in greater Cairo, Egypt. J. Egypt. Soc. Parasitol. 40, 2:459-64.

Hochberg, NS, Park, SY, Blackburn, BG, et al, 2007: Distribution of eosinophilic meningitis cases attributable to Angiostrongylus cantonensis, Hawaii. Emerg. Infect. Dis. 13: 1675-84.

Hughes, PA, Magnet, AD, Fishbain, JT, 2003: Eosinophilic meningitis: a case series report and review of the literature. Mil. Med. 168:817-24.

Ibrahim MM, 2007: Prevalence and intensity of Angiostrongylus cantonensis in freshwater snails in relation to some ecological and biological factors. Parasite 14, 1:61-70.

Ismail, Y, Arsura, EL, 1993: Eosinophilic meningitis associated with coccidioidomycosis. West J. Med. 158:300-08.

Jain, R, Prabhakar, S, Modi, M, et al, 2002: Naegleria meningitis: a rare survival. Neurol India 2002; 50:470.

Jin, E, Ma, D, Liang, Y, et al, 2005: MRI findings of eosinophilic myelomeningoencephalitis due to Angiostrongylus cantonensis. Clin. Radiol. 60:242-9.

Khalifa, RM, Ahmad, AK, Abdel-Hafeez, EH, Mosllem, FA, 2014: Present status of protozoan pathogens causing water-borne disease in northern part of El-Minia Governorate, Egypt. J. Egypt. Soc. Parasitol. 44, 3: 559-66.

Kesari, S, Batchelor, TT, 2003: Leptomeningeal metastases. Neurol. Clin. 21:25-9.

Koo, J, Pien, F, Kliks, MM, 1988: Angiostrongylus (Parastrongylus) eosinophilic meningitis. Rev. Infect. Dis. 10:1155-62.

Kuberski, T, 1979: Eosinophils in the cerebrospinal fluid. Ann. Int. Med. 91:70-8.

Schermoly, MJ, Hinthorn, DR, 1988: Eosinophilia in coccidioidomycosis. Arch. Int. Med. 148:895-9.

Kumar, V, Kyprianou, I, Keenan, JM, 2005: Ocular angiostrongyliasis: Removal of a live nematode from the anterior chamber. Eye 19:229-34.

Ligon, BL, 2005: Gnathostomiasis: A review of a previously localized zoonosis now-crossing numerous geographical boundaries. Semin. Pediatr. Infect. Dis.16:137-42.

LIndo, JF, Escoffery, CT, Reid, B, et al, 2004: Fatal autochthonous eosinophilic meningitis in a Jamaican child caused by Angiostrongylus cantonensis. Am. J. Trop. Med. Hyg. 70:425-32. 
Lo Re, V, Gluckman, SJ, 2003: Eosinophilic meningitis. Am. J. Med. 114:217-22.

Luessi, F, Sollors, J, Torzewski, M, et al, 2009: Eosinophilic meningitis due to Angiostrongylus cantonensis in Germany. J. Travel Med. 16:292.

Mayor, S, 2015: Malaria vaccine is partly effective in young children, study shows. BMJ. Apr 24;350:h2199.

Mets, MB, Noble, AG, Basti, S, et al, 2003: Eye findings of diffuse unilateral subacute neuroretinitis and multiple choroidal infiltrates associated with neural larva migrans due to Baylisascaris procyonis. Am. J. Ophthalmol. 135:888-94.

Moore, DA, Mc-Croddan, J, Dekumyoy, P, Chiodini, PL, 2003: Gnathostomiasis: an emerging imported disease. Emerg. Infect. Dis. 9:647-54.

Morsy, TA, 2014: Zoonotic myiasis in Egypt: With reference to nosocomial or hospitalacquired myiasis. J. Egypt. Soc. Parasitol. 44, 3:639-52.

Morsy, TA, Ibrahim, BB, Haridy, FM, Rifaat, MM, 2000: Trichinella encysted larvae in slaughtered pigs in Cairo (1995-1999). J. Egypt. Soc Parasitol. 30, 3:753-60.

Muller, W, Schorre, W, Suchenwirth, R, et al, 1978: A case of fatal Cryptococcus meningitis with intraventricular granuloma. Acta Neurochir. (Wien) 44:223-8.

Nashed, NN, Youssef, FG, Mansour, NS, 1991: Free-living amoebae in Egypt. 1. Naegleria gruberi and Naegleria fowleri. J. Egypt. Soc. Parasitol. 21, 1:31-42.

Naus, CW, Chipwete, J, Visser, LG, Zijlstra, EE, van Lieshout, L, 2003: The contribution made by schistosomaisis to non-traumatic disorders of the spinal cord in Malawi. Ann. Trop. Med. Parasitol. 97, 7: 711-21.

Nawa, Y, Hatz, C, Blum, J, 2005: Sushi delights and parasites: the risk of fish-borne and foodborne parasitic zoonoses in Asia. Clin. Infect. Dis. 41:1297-308.

Nikolić, S, Vujosević, M, Sasić, M, Poluga, J, Misić, S, et al, 1998: Neurologic manifestations in trichinosis. Srp. Arh. Celok. Lek. 126, 5/6:209-13

Othman, AA, Soliman, RH, 2015: Schistosomiasis in Egypt: A never-ending story? Acta Trop. 148:179-90.

Patey, O, Lacheheb, a, Dellion, S, et al, 1988: A rare case of cotrimoxazole-induced eosinophilic aseptic meningitis in an HIVinfected patient. Scand. J. Infect. Dis. 30:530-
8. Podwall, D, Gupta, R, Furuya, EY, et al, 2004: Angiostrongylus cantonensis meningitis presenting with facial nerve palsy. J. Neurol. 251:1280-9.

Pozio, E, 1991: Current status of food-borne parasitic zoonoses in Mediterranean and African regions. Southeast Asian J. Trop. Med. Pub. Hlth. 22:S85-7.

Prandota J, Gryglas, A, Fuglewicz, A, Zeslawska, A, Ujma-Czapska, B, et al, 2014: Recurrent headaches may be caused by cerebral toxoplasmosis. World J. Clin. Pediatr. 3, 3:59-68.

Punyagupta, S, Bunnag, T, Juttijudata, $P$, 1990: Eosinophilic meningitis in Thailand: Clinical and epidemiologic characteristics of 162 patients with myeloencephalitis probably caused by Gnathostoma spinigerum. J. Neurol. Sci. 96:241-8.

Pypen, Y, Oris, E, Meeuwissen, J, Laenen, MV, Van Gompel, F, et al, 20015: Late onset of Strongyloides stercoralis meningitis in a retired Belgian miner. Acta Clin. Belg. 2015 Jul 2:2295333715Y0000000048.

Ramirez-Avila, L, Slome, S, Schuster, FL, et al, 2009: Eosinophilic meningitis due to Angiostrongylus and Gnathostoma species. Clin. Infect. Dis. 48:322-32.

Rashed, AA, Khalil, HH, Morsy, AT, 2010: Zoonotic ectopic fascioliasis: Review and discussion. J. Egypt. Soc. Parasitol. 40, 3:591608.

Rifaat, MA, Sadek, MS, el-Azghal, HI, 1973: Isolation of Toxoplasma from a human placenta in Egypt. J. Trop. Med. Hyg. 76, 4: 90-1.

Robinson, A, Tannier, C, Magnaval, JF, 2002: Toxocara canis meningoradiculitis. Rev. Neurol. (Paris) 158:351-9.

Roussere, GP, Murray, WJ, Raudenbush, CB, et al, 2003: Raccoon roundworm eggs near homes and risk for larva migrans disease, California communities. Emerg. Infect. Dis. 9:1516-22.

Saleh AM, Ali Ha, Ahmed, SA, Hosny, SM, Morsy, TA, 2014: Screening of Toxoplasma gondii infection among childbearing age females and assessment of nurses' role in prevention and control of toxoplasmosis. J. Egypt. Soc, Parasitol. 44, 2:329-42.

Sartin, EA, Hendrix, CM, Dillehay, DL, Nicholls, BA, 1986: Cerebral cuterebrosis in a dog. J. Am. Vet Med. Assoc. 189, 10:1338 -42 . 
Sartori, AM, Ibrahim, KY, Nunes Westphalen, EV, Braz, LM, Oliveira, OC Jr, et al, 2007: Manifestations of Chagas disease (American trypanosomiasis) in patients with HIV/AIDS. Ann. Trop. Med. Parasitol. 101, 1:31-50.

Sawanyawisuth, K, Sawanyawisuth, K, 2008: Treatment of angiostrongyliasis. Trans. R. Soc. Trop. Med. Hyg. 102:990-9.

Sawanyawisuth, K, Tiamkao, S, Nitinavakarn, B, et al, 2005: MR imaging findings in Cauda equina gnathostomiasis. AJNR Am. J. Neuroradiol. 26:39-46.

Schuster, FL, Visvesvara, GS, 2004: Freeliving amoebae as opportunistic and nonopportunistic pathogens of humans and animals. Int. J. Parasitol. 34:1001-8.

Scott, TF, 1988: A new cause of cerebrospinal fluid eosinophilia: Neurosarcoidosis. Am. J. Med. 84:973-9.

Sharma, H, Dayal, D, Agrawal, SP, 1989: Nasal myiasis: review of 10 years experience. J. Laryngol. Otol. 103, 5:489-91.

Shaumar, NF, Mohammed, SK, Mohammed, SA, 1989: Keys for identification of species of family Calliphoridae (Diptera) in Egypt. J. Egypt. Soc. Parasitol. 19, 2:669-81.

Sheikh, J, Weller, PF, 2007: Clinical overview of hypereosinophilic syndromes. Immunol. Allergy Clin. North Am. 27:333-40.

Shih, RY, Koeller, KK, 2015: Bacterial, fungal, and parasitic infections of the central nervous system: radiologic-pathologic correlation and historical perspectives: from the radiologic pathology archives. Radiographics 35, 4:1141-69.

Slom, TJ, Cortese, MM, Gerber, SI, Jones, RC, Holtz, TH, et al, 2002: An outbreak of eosinophilic meningitis caused by Angiostrongylus cantonensis in travelers returning from the Caribbean. N. Engl. J. Med. 346, 9: 668-75.

Steyskal, G, El-Bialy, S, 1967: A List of Egyptian Diptera with a Bibliography and Key to Families. Tech. Bull. No. 3; Agriculture Ministry.

Tefferi, A, 2005: Blood eosinophilia: a new paradigm in disease classification, diagnosis, and treatment. Mayo Clin. Proc. 80:75-82.

Terterov, S, Taghva, A, MacDougall, M, Giannotta, S, 2010: Posttraumatic human cerebral myiasis. World Neurosurg. 73, 5: 557-9.

Traynelis, VC, Powell, RG, Koss, W, et al, 1988: Cerebrospinal fluid eosinophilia and sterile shunt malfunction. Neurosurgery 23 : 645-52.

Tsai, HC, Lee, SS, Huang, CK. et al, 2004: Outbreak of eosinophilic meningitis associated with drinking raw vegetable juice in southern Taiwan. Am. J. Trop. Med. Hyg. 71: 222-30.

Tsai, HC, Liu, YC, Kunin, CM, et al, 2001: Eosinophilic meningitis caused by Angiostrongylus cantonensis: Report of 17 cases. Am. J. Med. 111:109-16.

Tsai, HC, Liu, YC, Kunin, CM, et al, 2003: Eosinophilic meningitis caused by Angiostrongylus cantonensis associated with eating raw snails: correlation of brain magnetic resonance imaging scans with clinical findings. Am. J. Trop. Med. Hyg. 68:281-9.

Tung, H, Raffel, C, McComb, JG, 1991: Ventricular cerebrospinal fluid eosinophilia in children with ventriculoperitoneal shunts. J. Neurosurg. 75:541-8.

Uchida, K, Tateyama, S, Yamaguchi, R, Rostami, M, Kadota, K, 1993: Eosinophilic meningitis in two cows. J. Vet. Med Sci. 55, 6:1071-2.

Valadas, E, Badura, R, Marques, T, Neno, M, Boura, M, et al, 2015: A case of imported neurocysticercosis in Portugal. J. Infect. Dev. Ctries. 9, 1:114-7.

Viñuelas, J, García-Alonso, M, Ferrando, L, Navarrete, I, Molano, I, et al, 2001: Meningeal leishmaniosis induced by Leishmania infantum in naturally infected dogs. Vet. Parasitol. 101, 1:23-7.

Visvesvara, GS, Maguire, JH, 2006: Pathogenic and opportunistic free-living amebas: Acanthamoeba spp., Balamuthia mandrillaris, Naegleria folweri, and Sappina diploidia. In: Tropical Infectious Diseases: Principles, Pathogens and Practice, $2^{\text {nd }}$ ed. Vol 2, Guerrant, R, Walker, DH, Weller, PF, (Eds), Churchill Livingstone, Philadelphia.

Wishahy, AO, Rifaat, MA, Morsy, TA, elNaggar, BA, 1972: Toxoplasmosis in children with some neurological manifestations. J. Trop. Med. Hyg. 75, 12:255-6.

Xia, Y, Ju, Y, Chen, J, You, C, 2015: Cerebral paragonimiasis: A retrospective analysis of 27 cases. J. Neurosurg. Pediatr. 15, 1:1016.

Zhang, SN, He, QX, Yang, NB, Ni, SL, Lu, MQ, 2015: Isoniazid-induced drug rash with eosinophilia \& systemic symptoms (DRESS) syndrome presenting as acute eosinophilic myocarditis. Int. Med. 54, 10: 1227-30. 